\title{
OPEN Maximum oxygen consumption and quantification of exercise intensity in untrained male Wistar rats
}

\author{
Fei Qin ${ }^{1,2,6}$, Yanan Dong ${ }^{1,5,6}$, Songtao Wang ${ }^{3}$, Minxiao Xu ${ }^{1}$, Zhongwei Wang ${ }^{1}$, Chaoyi Qu ${ }^{1}$, \\ Yan Yang ${ }^{4}$ \& Jiexiu Zhao ${ }^{1 \bowtie}$
}

This study aimed to explore a valid test protocol for measuring $\mathrm{VO}_{2 \max }$ in healthy untrained male Wistar rats of different ages and quantifying the exercise intensity $\left(\% \mathrm{VO}_{2 \max }\right)$ of running under different treadmill grades and speeds. The test protocols and $\% \mathrm{VO}_{2 \max }$ will provide a reference for the design of exercise intensity. We tested male Wistar rats aged 4 weeks, 10 weeks, 10 months and 16 months old with three test protocols (Procedure 1 [P1], 2 [P2] and 3 [P3]) for each age group to quantify $\mathrm{VO}_{2 \max }$. We analysed $\mathrm{VO}_{2 \max }$ respiratory exchange ratio and test duration to determine an optimal test protocol of $\mathrm{VO}_{2 \max }$ for different age groups. We used the optimal test protocol to explore the changes in age-related $\mathrm{VO}_{2 \max }$. Finally, $\% \mathrm{VO}_{2 \max }$ of running under different treadmill speeds and grades was quantified. $\mathrm{VO}_{2 \max }$ of Wistar rats decreased significantly after the age of 4 weeks $(p<0.05)$. The optimum $\mathrm{VO}_{2 \max }$ can be induced by personalised protocols for different ages. In 4-week-old Wistar rats, the highest $\mathrm{VO}_{2 \max }$ values were attained by $\mathrm{P} 1\left(104.4 \pm 6.9 \mathrm{~mL} \cdot \mathrm{kg}^{-1} \cdot \mathrm{min}^{-1}, p=0.032\right)$. The highest $\mathrm{VO}_{2 \max }$ value $\left(84.7 \pm 3.7 \mathrm{~mL} \cdot \mathrm{kg}^{-1} \cdot \mathrm{min}^{-1}, p=0.037\right)$ of 8-week-old Wistar rats was attained in $\mathrm{P} 2$. In 10-month-old Wistar rats, the highest $\mathrm{VO}_{2 \max }$ value was obtained in $\mathrm{P} 3\left(63.3 \pm 1.7 \mathrm{~mL} \cdot \mathrm{kg}^{-1} \cdot \mathrm{min}^{-1}\right)$. This work could be used as a reference for assessing aerobic capacity in studies on exercise intervention with untrained male Wistar rats. However, the $\% \mathrm{VO}_{2 \max }$ measurements at various treadmill speeds and grades only apply to untrained male Wistar rats.

Cardiorespiratory fitness (CRF) reflects the integrated ability to transport oxygen from the atmosphere to the mitochondria for performing large-muscle, dynamic, and moderate-to-vigorous intensity exercises for prolonged time periods. CRF is directly related to the integrated function of numerous systems, including the nervous, respiratory, cardiovascular and musculoskeletal systems ${ }^{1-2}$. CRF is considered a reflection of total body health. Low CRF is associated with a high risk of cardiovascular diseases, all-cause mortality and various types of cancer ${ }^{3-5}$. Hence, the American Heart Association (2016) regarded CRF as a new clinical vital sign with equal importance as the heart rate, blood pressure, respiration and body temperature ${ }^{1}$. CRF can be measured directly, expressed as maximal oxygen consumption $\left(\mathrm{VO}_{2 \max }\right)$ or estimated from the peak work rate achieved on a treadmill, a cycle ergometer or through non-exercise algorithms ${ }^{6}$. $\mathrm{VO}_{2 \max }$ is the criterion measure of $\mathrm{CRF}^{2}$. In sports science, $\mathrm{VO}_{2 \max }$ has been used extensively to evaluate CRF and quantify exercise intensity for general populations and professional athletes ${ }^{7,8}$. Exercise intensity is a critical factor for people to achieve beneficial effects from physical activities. Such intensity is usually determined by $\mathrm{VO}_{2 \max }$ in the experimental design of sports science; thus, an objective and reliable test protocol should be formulated for $\mathrm{VO}_{2 \max }$ measurement ${ }^{9}$.

At present, $\mathrm{VO}_{2 \max }$ measurement and assessment have been well solved in human experiments and practices but are unsatisfactory in animal experiments. The accurate acquisition of $\mathrm{VO}_{2 \max }$ for experimental animals is also necessary for mechanism research in sports science. Bedford et al. developed and standardised the first

${ }^{1}$ China Institute of Sport Science, No. 11 Tiyuguan Road, Dongcheng District, Beijing 100061, China. ${ }^{2}$ School of Physical Education, Jinan University, Guangzhou 510632, China. ${ }^{3}$ School of Physical Education and Sport Science, South China Normal University, Guangzhou 510006, China. ${ }^{4}$ Department of Kinesiology and Community Health, University of Illinois at Urbana-Champaign, Champaign 61801, USA. ${ }^{5}$ Beijing Institute of Sports Science, Beijing 100075, China. ${ }^{6}$ These authors contributed equally: Fei Qin and Yanan Dong. ${ }^{\circledR}$ email: zhaojiexiu@ciss.cn 


\begin{tabular}{|c|c|c|c|}
\hline Parameters & P1 & P2 & P3 \\
\hline \multicolumn{4}{|l|}{4 weeks old } \\
\hline $\mathrm{VO}_{2 \max }\left(\mathrm{mL} \mathrm{kg}^{-1} \min ^{-1}\right)$ & $104.4 \pm 6.9$ & $103.8 \pm 8.9$ & $95.3 \pm 6.9^{* \#}$ \\
\hline RER & $1.07 \pm 0.24$ & $0.98 \pm 0.29^{*}$ & $1.04 \pm 0.45^{\#}$ \\
\hline Completion time (min) & $24.14 \pm 2.63$ & $28.50 \pm 2.81^{*}$ & $21.31 \pm 2.5^{\#}$ \\
\hline Induction rate & $75 \%$ & $63 \%$ & $63 \%$ \\
\hline Injured rats (n) & 2 & 2 & 0 \\
\hline \multicolumn{4}{|l|}{8 weeks old } \\
\hline $\mathrm{VO}_{2 \max }\left(\mathrm{mL} \mathrm{kg}^{-1} \mathrm{~min}^{-1}\right)$ & $79.8 \pm 4.4$ & $84.7 \pm 3.7^{\star}$ & $80.3 \pm 3.5$ \\
\hline RER & $1.04 \pm 0.03$ & $1.02 \pm 0.03^{*}$ & $1.05 \pm 0.02^{\#}$ \\
\hline Completion time (min) & $20.25 \pm 3.83$ & $24.00 \pm 4.93$ & $19.00 \pm 2.59^{\#}$ \\
\hline Induction rate & $70 \%$ & $75 \%$ & $70 \%$ \\
\hline Injured rats (n) & 2 & 1 & 0 \\
\hline \multicolumn{4}{|l|}{10 months old } \\
\hline $\mathrm{VO}_{2 \max }\left(\mathrm{mL} \mathrm{kg}^{-1} \mathrm{~min}^{-1}\right)$ & $58.3 \pm 2.2$ & $62.2 \pm 1.9$ & $63.3 \pm 1.7$ \\
\hline RER & $1.02 \pm 0.02$ & $1.03 \pm 0.02$ & $1.07 \pm 0.01$ \\
\hline Completion time (min) & $14.50 \pm 0.85$ & $20.72 \pm 1.43^{*}$ & $18.83 \pm 1.38^{*}$ \\
\hline Induction rate & $58 \%$ & $75 \%$ & $75 \%$ \\
\hline Injured rats (n) & 4 & 2 & 0 \\
\hline
\end{tabular}

Table 1. Related indicators of $\mathrm{VO}_{2 \max }$ in various test procedures for untrained male Wistar rats. All values are presented as mean $\pm \mathrm{SD}, n=9$ for each group. ${ }^{\star} p<.0 .05$ versus $\mathrm{P} 1 ;{ }^{*} p<.0 .05$ versus P2. P1: Procedure $1, \mathrm{P} 2$ : Procedure 2 and P3: Procedure 3. Induction rate: a ratio of $\mathrm{VO}_{2 \max }$ induced cases to total tested rats' cases.

test protocol of $\mathrm{VO}_{2 \max }$ for rats ${ }^{10}$. However, the features of experimental rats have changed largely over the past 40 years since the Bedford experiment. Therefore, quantifying exercise intensity on the basis of $\mathrm{VO}_{2 \max }$ data from previous studies may cause a deviation in calculation and a failure to obtain the expected experimental results. Additionally, some studies ${ }^{11,12}$ adopted too low or high exercise intensity, and such an approach often reduced exercise motivation and willingness and consequently affected the acquisition of the highest value of $\mathrm{VO}_{2 \max }$ in rats. To solve the above-mentioned problems, several crucial factors must be considered, namely, the differences in age, sex, strains, health status (health and disease) and training levels affecting the effectiveness of $\mathrm{VO}_{2 \max }$ test protocols $s^{10,12,13}$. For several special groups, a series of individualised $\mathrm{VO}_{2 \max }$ test protocols is needed. For instance, separate designs for $\mathrm{VO}_{2 \max }$ test protocols must be created for the oestrus cycle, perimenopausal period and menopausal period of female rats. Overall, effectively inducing the highest $\mathrm{VO}_{2 \max }$ value in experimental animals (rats) closely depends on the design of the test protocol, such as the intensity and duration of each exercise stage. Many clinical trials have implied that individualised test protocols of $\mathrm{VO}_{2 \max }$ should be utilised to obtain the largest $\mathrm{VO}_{2 \max }$ values for different populations. However, individualisation and differentiation for $\mathrm{VO}_{2 \max }$ tests in animal experiments according to age and health condition have yet to be conducted ${ }^{10,13,14}$. Hoydal reported that the working economy with low oxygen consumption improves during the training period ${ }^{12}$. Note that $\mathrm{VO}_{2 \max }$ will change in an exercise training program, and adjusting running speed according to $\mathrm{VO}_{2 \max }$ is necessary. Given the above factors, a series of work on individualised test protocols of $\mathrm{VO}_{2 \max }$ and a relative intensity calculation formula must be carried out in the future.

This study designed a series of standardised exercise protocols to measure $\mathrm{VO}_{2 \max }$ of male Wistar rats with the following objectives: (1) establishing a valid, reliable and individualised test protocol to measure $\mathrm{VO}_{2 \max }$ of male Wistar rats in different age groups; (2) exploring the relationship of $\mathrm{VO}_{2 \max }$ and age in male Wistar rats; and (3) quantifying the corresponding exercise intensity $\left(\% \mathrm{VO}_{2 \max }\right)$ of different treadmill grades and speeds in untrained male Wistar rats with different ages.

\section{Results}

$\mathrm{VO}_{2 \max }$ test protocol for male Wistar rats in different age groups. Table 1 shows the results of $\mathrm{VO}_{2 \max }$ indicators across the three procedures in 4-week-old Wistar rats. The induction rate of P1 achieved 75\%, which was higher than those of P2 (63\%) and P3 (63\%). The $\mathrm{VO}_{2 \max }$ values in P1 $\left(104.4 \pm 6.9 \mathrm{~mL} \cdot \mathrm{kg}^{-1} \cdot \mathrm{min}^{-1}\right.$ vs. $\left.95.3 \pm 6.9 \mathrm{~mL} \cdot \mathrm{kg}^{-1} \cdot \mathrm{min}^{-1}, p=0.032\right)$ and $\mathrm{P} 2\left(103.8 \pm 8.9 \mathrm{~mL} \cdot \mathrm{kg}^{-1} \cdot \mathrm{min}^{-1} \mathrm{vs} .95 .3 \pm 6.9 \mathrm{~mL} \cdot \mathrm{kg}^{-1} \cdot \mathrm{min}^{-1}\right.$, $p=0.045)$ were obviously higher than those in P3. However, the completion time of P1 was significantly shorter than that of P2 $(24.14 \pm 2.63 \mathrm{~min}$ vs. $28.50 \pm 2.81 \mathrm{~min}, p=0.006)$. Unfortunately, four 4 -week-old rats were injured in P1 and P2 because of poor adaptation to high treadmill speed.

As shown in Table 1, the highest $\mathrm{VO}_{2 \max }$ value $\left(84.7 \pm 3.7 \mathrm{~mL} \cdot \mathrm{kg}^{-1} \cdot \mathrm{min}^{-1}, p=0.037\right)$ of 8 -week-old Wistar rats was attained in P2. However, P2 consumed more time than P3 did $(24.00 \pm 4.93$ min vs. $19.00 \pm 2.59$ min, $p=0.021$ ). In addition, two rats were injured in $\mathrm{P} 1$, and one was injured in $\mathrm{P} 2$.

Regarding the 10-month-old Wistar rats, the highest $\mathrm{VO}_{2 \max }$ value was found in $\mathrm{P} 3$ (Table 1). The test duration of $\mathrm{P} 1$ was remarkably shorter than those of $\mathrm{P} 2(14.50 \pm 0.85 \mathrm{~min}$ vs. $20.72 \pm 1.43 \mathrm{~min}, p=0.002)$ and $\mathrm{P} 3$ $(14.50 \pm 0.85 \mathrm{~min}$ vs. $18.83 \pm 1.38 \mathrm{~min}, p=0.001)$. However, four rats were injured in $\mathrm{P} 1$. The rats showed lower 


\begin{tabular}{|l|l|l|l|}
\hline Age & $\mathbf{V O}_{2 \max }\left(\mathrm{mL} \mathrm{kg}^{-1} \mathbf{~ m i n}^{-1}\right)$ & RER & Completion time $(\mathbf{m i n})$ \\
\hline 4 weeks & $105.6 \pm 4.8$ & $1.035 \pm 0.066$ & $25.08 \pm 3.69$ \\
\hline 8 weeks & $85.4 \pm 4.0^{*}$ & $1.034 \pm 0.544$ & $21.73 \pm 3.66^{\star}$ \\
\hline 10 months & $62.3 \pm 6.4^{* *}$ & $1.044 \pm 0.043$ & $16.71 \pm 2.67^{* *}$ \\
\hline 16 months & $56.2 \pm 2.5^{* \# \&}$ & $1.071 \pm 0.039^{* *}$ & $13.70 \pm 2.23^{* * \&}$ \\
\hline
\end{tabular}

Table 2. Influence of age on related indicators of $\mathrm{VO}_{2 \max }$ in untrained male Wistar rats. All values are presented as mean $\pm \mathrm{SD}, n=20$ for each group. ${ }^{\star} p<.0 .05$ versus 4 -week-old rats. ${ }^{*} p<.0 .05$ versus 8 -week-old rats. ${ }^{\&} p<0.05$ versus 10 -month-old rats.

\begin{tabular}{|c|c|c|c|c|c|c|c|c|c|c|c|}
\hline \multirow[b]{2}{*}{ Grade $\left(^{\circ}\right)$} & \multicolumn{11}{|c|}{ Speed $\left(\mathrm{m} \mathrm{min} \mathbf{m}^{-1}\right)$} \\
\hline & $\begin{array}{l}0 \\
\end{array}$ & 10 & 15 & 20 & 25 & 30 & 35 & 40 & 45 & 50 & 55 \\
\hline \multicolumn{12}{|l|}{0} \\
\hline $\begin{array}{l}\mathrm{VO}_{2}\left(\mathrm{~mL} \mathrm{~kg}^{-1}\right. \\
\left.\mathrm{min}^{-1}\right)\end{array}$ & $39.6 \pm 4.7$ & $55.5 \pm 7.7$ & $59.8 \pm 7.9$ & $61.3 \pm 7.9$ & $64.5 \pm 6.6$ & $70.6 \pm 5.4$ & $78.1 \pm 5.0$ & $85.8 \pm 4.4$ & $92.6 \pm 6.5$ & $101.6 \pm 4.3$ & $108.0 \pm 6.9$ \\
\hline$\% \mathrm{VO}_{2 \max }$ & $35.79 \pm 4.63$ & $52.05 \pm 4.59$ & $59.05 \pm 5.78$ & $60.84 \pm 5.56$ & $64.25 \pm 6.21$ & $70.11 \pm 5.80$ & $78.67 \pm 8.91$ & $86.65 \pm 7.47$ & $93.28 \pm 6.50$ & $95.59 \pm 2.88$ & 100 \\
\hline \multicolumn{12}{|l|}{5} \\
\hline $\begin{array}{l}\mathrm{VO}_{2}\left(\mathrm{~mL} \mathrm{~kg}^{-1}\right. \\
\left.\mathrm{min}^{-1}\right)\end{array}$ & $38.9 \pm 5.5$ & $55.9 \pm 4.6$ & $60.7 \pm 4.1$ & $65.5 \pm 4.6$ & $70.1 \pm 6.3$ & $76.3 \pm 7.3$ & $82.8 \pm 6.8$ & $91.2 \pm 7.7$ & $99.5 \pm 7.0$ & $106.2 \pm 4.4$ & $108.7 \pm 4.0$ \\
\hline$\% \mathrm{VO}_{2 \max }$ & $34.07 \pm 0.80$ & $52.26 \pm 8.57$ & $58.39 \pm 7.91$ & $63.13 \pm 8.10$ & $67.83 \pm 9.45$ & $73.96 \pm 11.27$ & $79.96 \pm 9.37$ & $88.03 \pm 8.91$ & $95.86 \pm 6.70$ & $97.34 \pm 4.03$ & 100 \\
\hline \multicolumn{12}{|l|}{10} \\
\hline $\begin{array}{l}\mathrm{VO}_{2}\left(\mathrm{~mL} \mathrm{~kg}^{-1}\right. \\
\left.\mathrm{min}^{-1}\right)\end{array}$ & $38.7 \pm 3.3$ & $55.3 \pm 6.8$ & $60.9 \pm 9.4$ & $69.1 \pm 6.0$ & $77.2 \pm 10.6$ & $85.1 \pm 10.0$ & $95.8 \pm 6.8$ & $98.9 \pm 6.8$ & $101.3 \pm 6.4$ & & \\
\hline$\% \mathrm{VO}_{2 \max }$ & $34.95 \pm 4.35$ & $52.18 \pm 5.36$ & $58.59 \pm 8.49$ & $65.72 \pm 7.19$ & $73.57 \pm 11.29$ & $81.30 \pm 12.04$ & $91.03 \pm 7.86$ & $94.59 \pm 7.53$ & $96.68 \pm 8.33$ & & \\
\hline \multicolumn{12}{|l|}{15} \\
\hline $\begin{array}{l}\mathrm{VO}_{2}\left(\mathrm{~mL} \mathrm{~kg}^{-1}\right. \\
\left.\min ^{-1}\right)\end{array}$ & $37.9 \pm 2.7$ & $56.0 \pm 5.0$ & $65.4 \pm 5.8$ & $76.5 \pm 6.4$ & $85.0 \pm 4.7$ & $89.4 \pm 5.0$ & $93.8 \pm 4.6$ & $98.0 \pm 5.0$ & & & \\
\hline$\% \mathrm{VO}_{2 \max }$ & $34.22 \pm 4.21$ & $53.70 \pm 7.63$ & $62.76 \pm 9.80$ & $72.55 \pm 10.15$ & $80.36 \pm 7.16$ & $85.78 \pm 4.85$ & $89.46 \pm 3.15$ & $93.26 \pm 4.41$ & & & \\
\hline
\end{tabular}

Table 3. $\% \mathrm{VO}_{2 \max }$ in different treadmill speeds and grades for 4-week-old untrained male Wistar rats. All values are presented as mean $\pm \mathrm{SD}, n=10$ for each group. $\% \mathrm{VO}_{2 \max }$ is the ratio of $\mathrm{VO}_{2}$ to $\mathrm{VO}_{2 \max }$.

compliance in P1 compared with the other procedures. Therefore, the induction rate of $\mathrm{VO}_{2 \max }$ in $\mathrm{P} 1$ was relatively low (58\%).

Relationship of $\mathrm{VO}_{2 \max }$ and ages in male Wistar rats. $\mathrm{VO}_{2 \max }$ of 8-week-old rats declined significantly compared with that of 4-week-old rats $\left(105.6 \pm 4.8 \mathrm{~mL} \cdot \mathrm{kg}^{-1} \cdot \mathrm{min}^{-1} \mathrm{vs} 85.4 \pm 4.0 \mathrm{~mL} \cdot \mathrm{kg}^{-1} \cdot \mathrm{min}^{-1}\right.$, $p<0.05$, Table 2). In addition, $\mathrm{VO}_{2 \max }$ of 10 -month-old rats presented a downward trend compared with that of 8-week-old rats $\left(85.4 \pm 4.0 \mathrm{~mL} \cdot \mathrm{kg}^{-1} \cdot \mathrm{min}^{-1} \mathrm{vs} .62 .3 \pm 6.4 \mathrm{~mL} \cdot \mathrm{kg}^{-1} \cdot \mathrm{min}^{-1}, p<0.05\right.$, Table 2). Compared with 10-month-old rats, 16 -month-old rats exhibited a $9.8 \%$ decline of $\mathrm{VO}_{2 \max }\left(62.3 \pm 6.4 \mathrm{~mL} \cdot \mathrm{kg}^{-1} \cdot \mathrm{min}^{-1} \mathrm{vs}\right.$. $56.2 \pm 2.5 \mathrm{~mL} \cdot \mathrm{kg}^{-1} \cdot \mathrm{min}^{-1}, p<0.05$, Table 2).

Quantification of the corresponding exercise intensity $\left(\% \mathrm{VO}_{2 \max }\right)$. Tables $3,4,5$ show the relative exercise intensity $\left(\% \mathrm{VO}_{2 \max }\right)$ in different grades $\left(0^{\circ}, 5^{\circ}, 10^{\circ}\right.$ and $\left.15^{\circ}\right)$ and speeds (increased by 5 or $3 \mathrm{~m} \mathrm{~min}^{-1}$ every $3 \mathrm{~min}$ ) among 4 -week-old, 8 -week-old and 16-month-old Wistar rats. We divided the actual measured value of $\mathrm{VO}_{2}$ when the rats were running at different speeds and grades by $\mathrm{VO}_{2 \max }$ to obtain the corresponding $\% \mathrm{VO}_{2 \max }$ intensity. For example, at a treadmill speed of $10 \mathrm{~m} \mathrm{~min}^{-1}$ and slope of $0^{\circ}, \mathrm{VO}_{2}$ of 8 -week-old Wistar rats was $41.1 \pm 2.0 \mathrm{~mL} \mathrm{~kg}^{-1} \mathrm{~min}^{-1}$ and equivalent to $48.49 \pm 2.79 \% \mathrm{VO}_{2 \max }$. When the speed was $45-50 \mathrm{~m} \mathrm{~min}^{-1}$, the relative workload was $95 \%-100 \% \mathrm{VO}_{2 \max }$ (Table 5). The data in Tables 3, 4, 5 can be used to estimate the exercise intensity at baseline for male Wistar rats at different ages. Note that these data only apply to untrained rats, and that the relative exercise intensity $\left(\% \mathrm{VO}_{2 \max }\right)$ cannot be used as a reference for trained rats.

\section{Discussion}

In this study, we designed three test protocols to measure $\mathrm{VO}_{2 \max }$. Preliminary experiments indicated that the treadmill speed of less than $9 \mathrm{~m} \mathrm{~min}^{-1}$ easily results in backward running and reduced exercise motivation in rats. In accordance with the test protocols by Hoydal et al. and Wisloff et al. ${ }^{12,13}$, the initial speed should be more than $9 \mathrm{~m} \mathrm{~min}^{-1}$. In accordance with human studies, stable oxygen uptake could be achieved after 3-4 min in each exercise stage ${ }^{15}$. Similarly, stable oxygen uptake could usually be achieved within $3 \mathrm{~min}$ in animal tests. Therefore, we set the duration of each exercise stage as $3 \mathrm{~min}$, which was consistent with the reports of Chavanelle et al. and Bedford et al. ${ }^{10,16}$. Moreover, several young rats were prone to demonstrate a sham plateau response that may be 


\begin{tabular}{|c|c|c|c|c|c|c|c|c|c|c|}
\hline \multirow[b]{2}{*}{ Grade $\left(^{\circ}\right)$} & \multicolumn{10}{|c|}{ Speed $\left(\mathrm{m} \min ^{-1}\right)$} \\
\hline & 0 & 10 & 15 & 20 & 25 & 30 & 35 & 40 & 45 & 50 \\
\hline \multicolumn{11}{|l|}{0} \\
\hline $\mathrm{VO}_{2}\left(\mathrm{~mL} \mathrm{~kg}^{-1} \mathrm{~min}^{-1}\right)$ & $27.2 \pm 4.5$ & $41.1 \pm 2.0$ & $48.9 \pm 5.0$ & $54.3 \pm 8.0$ & $58.8 \pm 9.1$ & $61.2 \pm 6.7$ & $68.3 \pm 9.0$ & $73.8 \pm 5.9$ & $80.6 \pm 1.5$ & $87.1 \pm 2.9$ \\
\hline$\% \mathrm{VO}_{2 \max }$ & $34.62 \pm 6.80$ & $48.49 \pm 2.79$ & $56.38 \pm 4.82$ & $61.30 \pm 6.39$ & $66.98 \pm 9.83$ & $72.64 \pm 9.73$ & $79.64 \pm 10.07$ & $89.81 \pm 6.27$ & $95.96 \pm 4.57$ & 100 \\
\hline \multicolumn{11}{|l|}{5} \\
\hline $\mathrm{VO}_{2}\left(\mathrm{~mL} \mathrm{~kg}^{-1} \mathrm{~min}^{-1}\right)$ & $30.3 \pm 5.8$ & $43.7 \pm 5.4$ & $49.0 \pm 7.3$ & $54.7 \pm 9.4$ & $60.7 \pm 11.1$ & $70.2 \pm 9.9$ & $78.4 \pm 8.0$ & $79.0 \pm 5.8$ & $89.0 \pm 4.0$ & \\
\hline \multicolumn{11}{|l|}{10} \\
\hline $\mathrm{VO}_{2}\left(\mathrm{~mL} \mathrm{~kg}^{-1} \mathrm{~min}^{-1}\right)$ & $28.6 \pm 5.6$ & $44.0 \pm 5.8$ & $50.8 \pm 6.9$ & $59.2 \pm 8.5$ & $67.4 \pm 9.2$ & $76.5 \pm 3.8$ & $84.7 \pm 5.6$ & $90.3 \pm 5.5$ & & \\
\hline$\% \mathrm{VO}_{2 \max }$ & $33.25 \pm 5.21$ & $51.37 \pm 5.20$ & $59.51 \pm 8.74$ & $69.65 \pm 12.55$ & $81.72 \pm 11.70$ & $89.89 \pm 9.09$ & $97.60 \pm 3.04$ & 100 & & \\
\hline \multicolumn{11}{|l|}{15} \\
\hline $\mathrm{VO}_{2}\left(\mathrm{~mL} \mathrm{~kg}^{-1} \mathrm{~min}^{-1}\right)$ & $28.3 \pm 2.4$ & $44.2 \pm 2.9$ & $54.4 \pm 6.7$ & $63.3 \pm 9.8$ & $66.8 \pm 7.8$ & $68.9 \pm 0.3$ & $74.0 \pm 3.4$ & & & \\
\hline$\% \mathrm{VO}_{2 \max }$ & $33.88 \pm 5.72$ & $52.66 \pm 3.26$ & $63.93 \pm 5.84$ & $74.51 \pm 8.41$ & $84.44 \pm 6.47$ & $85.57 \pm 4.08$ & $90.43 \pm 5.21$ & & & \\
\hline
\end{tabular}

Table 4. $\% \mathrm{VO}_{2 \max }$ in different treadmill speeds and grades for 8-week-old untrained male Wistar rats. All values are presented as mean $\pm \mathrm{SD}, n=10$ for each group. $\% \mathrm{VO}_{2 \max }$ is the ratio of $\mathrm{VO}_{2}$ to $\mathrm{VO}_{2 \max }$.

\begin{tabular}{|c|c|c|c|c|c|c|c|}
\hline \multirow[b]{2}{*}{ Grade $\left(^{\circ}\right)$} & \multicolumn{7}{|c|}{ Speed $\left(\mathrm{m} \mathrm{min}{ }^{-1}\right)$} \\
\hline & 0 & 12 & 15 & 18 & 21 & 24 & 27 \\
\hline \multicolumn{8}{|l|}{0} \\
\hline $\mathrm{VO}_{2}\left(\mathrm{~mL} \mathrm{~kg}^{-1} \mathrm{~min}^{-1}\right)$ & $19.3 \pm 3.4$ & $31.5 \pm 4.4$ & $40.9 \pm 4.5$ & $47.7 \pm 5.5$ & $51.3 \pm 5.9$ & $54.1 \pm 4.8$ & $54.7 \pm 3.3$ \\
\hline$\% \mathrm{VO}_{2 \max }$ & $35.04 \pm 6.68$ & $57.04 \pm 6.89$ & $74.48 \pm 9.51$ & $86.62 \pm 11.40$ & $92.95 \pm 10.07$ & $98.31 \pm 2.21$ & 100 \\
\hline \multicolumn{8}{|l|}{5} \\
\hline $\mathrm{VO}_{2}\left(\mathrm{~mL} \mathrm{~kg}^{-1} \mathrm{~min}^{-1}\right)$ & $19.0 \pm 2.5$ & $32.4 \pm 3.5$ & $41.1 \pm 5.7$ & $47.4 \pm 5.3$ & $51.7 \pm 4.8$ & $52.9 \pm 5.3$ & \\
\hline$\% \mathrm{VO}_{2 \max }$ & $35.23 \pm 8.99$ & $61.77 \pm 6.35$ & $78.16 \pm 9.13$ & $90.28 \pm 7.73$ & $98.72 \pm 2.27$ & 100 & \\
\hline \multicolumn{8}{|l|}{10} \\
\hline $\mathrm{VO}_{2}\left(\mathrm{~mL} \mathrm{~kg}^{-1} \mathrm{~min}^{-1}\right)$ & $17.8 \pm 2.7$ & $31.4 \pm 3.2$ & $39.8 \pm 3.6$ & $48.2 \pm 5.1$ & $52.1 \pm 5.4$ & & \\
\hline$\% \mathrm{VO}_{2 \max }$ & $34.53 \pm 7.02$ & $60.42 \pm 5.81$ & $76.76 \pm 7.39$ & $92.46 \pm 2.16$ & 100 & & \\
\hline
\end{tabular}

Table 5. $\% \mathrm{VO}_{2 \max }$ in different treadmill speeds and grades for 16 -month-old untrained male Wistar rats. All values are presented as mean $\pm \mathrm{SD}, n=10$ for each group. $\% \mathrm{VO}_{2 \max }$ is the ratio of $\mathrm{VO}_{2}$ to $\mathrm{VO}_{2 \max }$.

related to the duration of each exercise stage ${ }^{17}$. Furthermore, age was proportional to the duration needed for stabilising oxygen uptake in each exercise stage. Thus, the duration of each exercise stage should be adjusted in accordance with the subjects' age. If the duration is unreasonably long, then the oxygen consumption would not increase continuously, thereby underestimating the $\mathrm{VO}_{2}$ peak and reducing running economy ${ }^{12,17}$. Regarding the termination criteria of the $\mathrm{VO}_{2 \max }$ test, Taylor et al. and Taylor et al. used the $\mathrm{VO}_{2 \max }$ plateau response in their studies, that is, an under $5 \%$ increase in $\mathrm{VO}_{2}$ with an increase in work intensity ${ }^{18,19}$. However, no significant statistical differences were found between plateau and non-plateau results in the same animals ${ }^{10}$. Consequently, the respiratory exchange ratio (RER), exhaustion state and blood lactate acid should be considered in addition to the volume change of $\mathrm{O}_{2}$ consumption when evaluating the standard of $\mathrm{VO}_{2 \max }$.

In the prophase of this study, we attempted to use Bedford et al.s protocol. However, the protocol resulted in a low measured value of $\mathrm{VO}_{2 \max }$ and a high injury rate probably because of the overly high treadmill speed in each stage ${ }^{10}$. Thus, we appropriately reduced the increasing amplitude of speed and slope and named this procedure $\mathrm{P} 1$. As shown in Table 2, the highest $\mathrm{VO}_{2 \max }$ value of $75 \%$ in 4 -week-old Wistar rats was induced by $\mathrm{P} 1$. Remarkably, the induction rate of $\mathrm{VO}_{2 \max }$ in $\mathrm{P} 1$ declined with the increase in age of Wistar rats (Table 1). During testing in $\mathrm{P} 1$, the older rats showed more serious stress response, poorer compliance and a higher injury rate (four injured rats) compared with the young rats. Meanwhile, few older rats reached the exhaustion state, and a low induction rate of $\mathrm{VO}_{2 \max }(58 \%)$ was obtained. Overall, $\mathrm{P} 1$ was more suitable for young rats than old rats, and the actual $\mathrm{VO}_{2 \max }$ value could be easily obtained. With regard to the incremental speed protocol (P2), the completion duration was the longest in the three procedures for all ages of rats. This result may be related to the single changing parameter, that is, treadmill speed. Therefore, an unreasonably low or high speed affected the final test results of $\mathrm{VO}_{2 \max }$. On this basis, the incremental speed of each stage in $\mathrm{P} 2$ should be adjusted in accordance with the rats' age, physical condition and exercise capacity.

Compared with the young rats, older ones suffered more stress as speed increased. Hence, extremely high speed often reduced motivation and willingness for treadmill running. The rapid increase in speed in a short time could not fully mobilise the cardiorespiratory function in rats, thereby affecting the stress response. Thus, in P3, the treadmill speed was gradually increased until $80-85 \%$ of $\mathrm{VO}_{2 \max }$ intensity was reached. This speed was maintained, and the slope was increased for each stage. In this manner (P3), older rats still showed higher 
compliance than young ones during the latest age of the test, thereby presenting an ideal $\mathrm{VO}_{2 \max }$ value. Similar results were also found by Wisloff et al. and Fitzsimons et al. ${ }^{13,20}$. This similarity may be related to the increased treadmill slope that could enable considerably large muscles to work under a relatively low running speed, thereby reducing the stress response in rats ${ }^{13,20}$. Meanwhile, the risk of injury obviously declined in P3 for the older rats. The 4- and 8-week-old rats finished the $\mathrm{VO}_{2 \max }$ test in $\mathrm{P} 3$, and all rats were exhausted. Moreover, the highest $\mathrm{VO}_{2 \max }$ value in $\mathrm{P} 3$ was difficult to obtain in comparison with those in P1 and P2. This difficulty was possibly due to the progressive increasing slope that could not fully activate the cardiopulmonary function of young rats to the maximum level before exhaustion ${ }^{16}$. Thus, when measuring $\mathrm{VO}_{2 \max }$, slope-based programs (P3) should be given to older rats, whereas speed-based programs (P1 and P2) should be applied for young rats.

In the second stage of this study, we selected optimum test protocols obtained from the preceding research to quantify $\mathrm{VO}_{2 \max }$ of Wistar rats with different ages. As shown in Table 2, $\mathrm{VO}_{2 \max }$ in Wistar rats declined with age. This result was similar to those of Mazzeo et al. and Lawler et al. ${ }^{14,21}$. Our findings demonstrated the changing trend of $\mathrm{VO}_{2 \max }$ with age and provided a reference value of $\mathrm{VO}_{2 \max }$ in experimental rats for further studies.

A dose-response relationship must be observed strictly between exercise intensity/load and intervention effect in sports training and exercise prescription. Accurate exercise intensity $\left(\% \mathrm{VO}_{2 \max }\right)$ may only be obtained from directly measuring $\mathrm{VO}_{2 \max }$. Most studies failed to measure $\mathrm{VO}_{2 \max }$ because of lack of necessary equipment. Therefore, exercise intensity by $\% \mathrm{VO}_{2 \max }$, especially in animal experiments, could not be quantified accurately. Nonetheless, in this work, the relative exercise intensities at different treadmill grades and speeds were quantified by calculating $\% \mathrm{VO}_{2 \max }$ for the 4 -week-old, 8 -week-old and 16 -month-old male Wistar rats. Hence, this study (Tables $3,4,5)$ could provide a reference for the initial design of exercise intensity in the exercise intervention research on untrained male Wistar rats. The main reason for the above limitations was the improvement in working economy with low oxygen consumption during the training period, thereby shifting the relationship between $\% \mathrm{VO}_{2 \max }$ and treadmill grades and speeds significantly ${ }^{12,13}$. Note that the relative training intensities $\left(\% \mathrm{VO}_{2 \max }\right.$, Tables $\left.3,4,5\right)$ were only applied to untrained rats or subjects for the initial design intensity. Hoydal indicated that the control of exercise intensity and the integrated effects of training require regulation of running speed according to the serial measurements of $\mathrm{VO}_{2 \max }{ }^{12}$.

\section{Limitations}

Several limitations of this study should be noted. Firstly, differences in age, sex, strains and health status affected the test effects of $\mathrm{VO}_{2 \max }$; thus, a series of individualised protocols is needed. The $\mathrm{VO}_{2 \max }$ relative tests of male Wistar rats were part of our projects. In the future, the $\mathrm{VO}_{2 \max }$ tests of male Sprague-Dawley (SD) rats, the individualised protocol for designing different physiological states of female rats (the oestrus cycle, perimenopausal period and menopausal period) and the changes in $\mathrm{VO}_{2 \max }$ in several abnormal health statuses (obesity and chronic metabolic diseases) need further investigation. Secondly, the relative training intensity $\left(\% \mathrm{VO}_{2 \max }\right)$ was only applied to untrained rats or subjects for the initial design intensity. The indirect formula of $\mathrm{VO}_{2 \max }$ of rats during exercise training still needs more research support. Thirdly, in establishing the $\mathrm{VO}_{2 \max }$ test protocol for aging rats, we did not select 16 -month-old rats due to poor exercise performance and serious casualties. One 16-month-old rat could not complete all three protocols, so the comparison could not be carried out. Therefore, we selected younger old rats (10 months old) to finish the establishment and modification of the protocol. Lastly, a sham plateau occurred in the $\mathrm{VO}_{2 \max }$ test, especially for the young rats. This occurrence may be related to the exercise intensity and the duration of each stage. Moreover, this study did not provide specific recommendations for the optimal intensity and duration in each exercise stage for Wistar rats with different ages. Only one duration ( $3 \mathrm{~min}$ in each stage) was observed in our design. Thus, changes in duration should be observed in further studies.

\section{Conclusion}

Compared with the older Wistar rats, the young ones ( 4 and 8 weeks old) adapted to speed increase better in the $\mathrm{VO}_{2 \max }$ test. Hence, speed should be increased when designing the $\mathrm{VO}_{2 \max }$ test protocol for young Wistar rats. Conversely, under a moderate treadmill speed, older Wistar rats (10 and 16 months old) were more competent with increasing slope and more likely to reach the largest $\mathrm{VO}_{2 \max }$ value with lower stress responses and injury risks. The test program demonstrated that $\mathrm{VO}_{2 \max }$ declined with age in male Wistar rats. Finally, the relative exercise intensity $\left(\% \mathrm{VO}_{2 \max }\right)$ at different treadmill speeds and grades for male Wistar rats with different ages was quantified. Given the improvement in working economy with low oxygen consumption during the training period, $\% \mathrm{VO}_{2 \max }$ was only applied to untrained rats or subjects for the initial design intensity. Therefore, this study could be used as a reference for assessing aerobic capacity and designing exercise intensity in studies on exercise intervention with untrained male Wistar rats.

\section{Methods}

Experimental animals. Wistar rats aged 4 weeks (male, $174.64 \pm 57.06 \mathrm{~g}, \mathrm{n}=40$ ), 10 weeks (male, $372.30 \pm 49.56 \mathrm{~g}, \mathrm{n}=40$ ), 10 months (male, $616.74 \pm 63.50 \mathrm{~g}, \mathrm{n}=40$ ) and 16 months (male, $674.45 \pm 36.39 \mathrm{~g}$, $\mathrm{n}=40$ ) were housed separately, with a $12: 12 \mathrm{~h}$ light-dark cycle, $23{ }^{\circ} \mathrm{C} \pm 2{ }^{\circ} \mathrm{C}$ room temperature and $45 \%-55 \%$ humidity. Food and water were provided ad libitum. All animal procedures were performed in accordance with the experimental protocol approved by the Animal Ethical Committee of China Institute of Sports Science. After 1 week of adaptive feeding, all rats were trained to be familiar with the treadmill exercise program in 1 week. The maximum oxygen uptake was assessed with different test protocols.

Test procedures. Twenty rats were selected randomly from each age group (4-week-old, 10-week-old and 10-month-old groups). Each rat completed three exercise protocols in random order within a 3-day interval. When all three exercise protocols were accomplished, we analysed $\mathrm{VO}_{2 \max }$, $\mathrm{RER}$, completion time and induction 
(a)

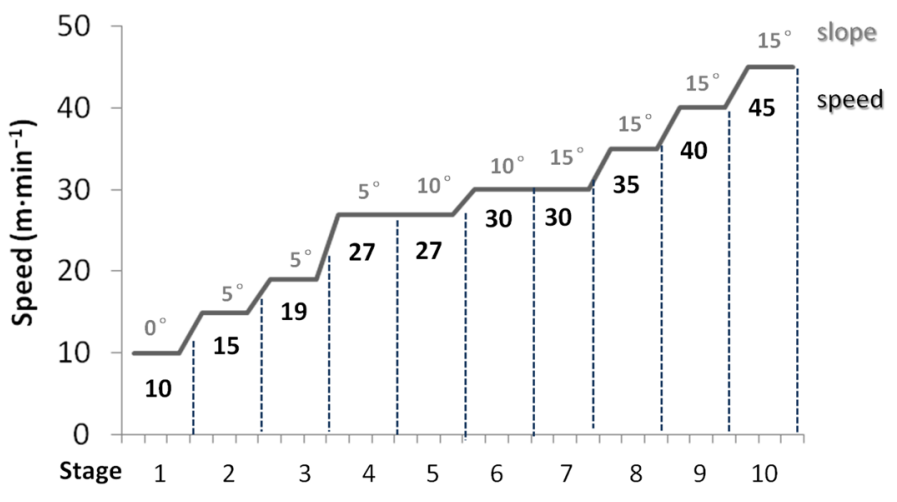

(b)

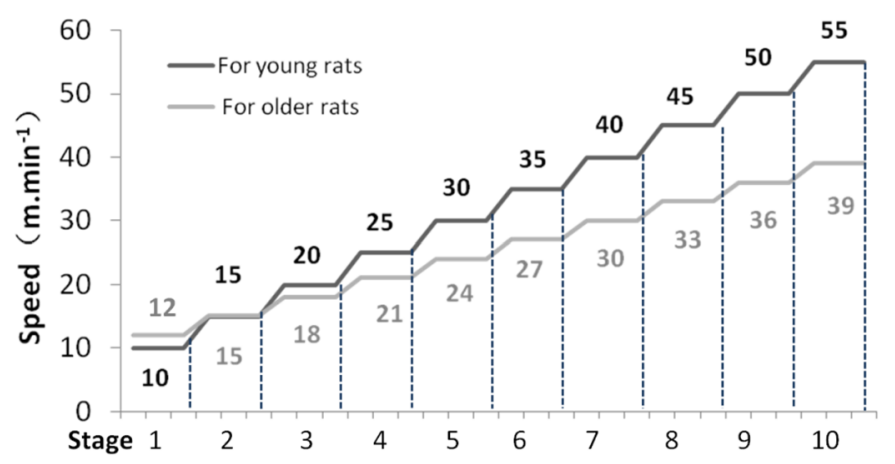

(c) slope was inclined by $5^{\circ}$ for every stage $\left(0-25^{\circ}\right)$

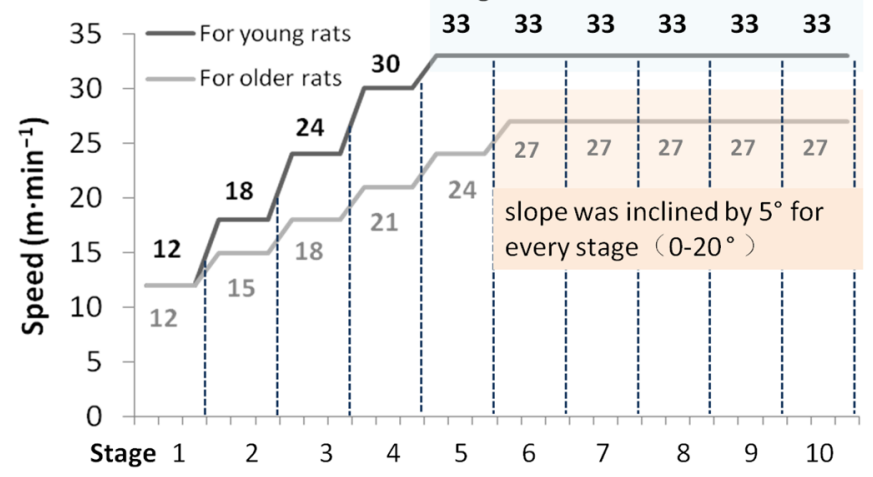

Figure 1. Treadmill testing procedure. (a) Treadmill testing procedure I. (b) Treadmill testing procedure II. (c) Treadmill testing procedure III. Each stage lasted for $3 \mathrm{~min}$.

rate (ratio of $\mathrm{VO}_{2 \max }$ induced cases to total tested rats' cases) to determine an optimal test protocol of $\mathrm{VO}_{2 \max }$ for different age groups. In the second stage, we randomly selected another 20 rats from the four groups to test $\mathrm{VO}_{2 \max }$ using the preceding optimal test protocol. Accordingly, we explored the change in age-related $\mathrm{VO}_{2 \max }$ in Wistar rats. Finally, the relationship between relative exercise intensity $\left(\% \mathrm{VO}_{2 \max }\right)$ and treadmill speed and slope was quantified in the Wistar rats groups aged 4 weeks, 10 weeks and 16 months.

Exercise protocol. Procedure 1 (P1) involved a continuous and progressive increase in speed and slope, and it was designed by modifying the protocol from Bedford et al. ${ }^{10}$ (Fig. 1a). Procedure 2 (P2) was an incremental speed protocol with a $0^{\circ}$ slope ${ }^{12,13}$. Treadmill speed was increased by $5 \mathrm{~m} \mathrm{~min}^{-1}$ every $3 \mathrm{~min}$ for young rats ( 4 week and 8 week age groups) or increased by $3 \mathrm{~m} \mathrm{~min}^{-1}$ for older rats (10 month age group) until the rats were exhausted (Fig. 1b). Procedure 3 (P3) was an incremental load protocol, in which speed was increased until approximately $80-85 \%$ of $\mathrm{VO}_{2 \max }$ was reached (the speed was determined according to previous pre-experimental results. Over this speed, the willingness to run in rats declined.). This speed was maintained, and the treadmill 
slope was inclined by $5^{\circ}$ for every stage until the rats were exhausted (Fig. 1c). Treadmill speed was increased by 6 and $3 \mathrm{~m} \mathrm{~min}^{-1}$ every 3 min until 33 and $27 \mathrm{~m} \mathrm{~min}^{-1}$ were achieved by the young and older rats, respectively. Rats may produce a stress response when faced with an unfamiliar environment and unaccustomed behaviours, such as running on a treadmill. Therefore, 1-week adaptive treadmill running was performed to reduce stress and guarantee ideal results.

The exercise intensity $\left(\% \mathrm{VO}_{2 \max }\right)$ corresponding to different treadmill speeds was quantified at four grades $\left(0^{\circ}\right.$, $5^{\circ}, 10^{\circ}$ and $\left.15^{\circ}\right)$ for 4 - and 8 -week-old rats and at three grades $\left(0^{\circ}, 5^{\circ}\right.$ and $\left.10^{\circ}\right)$ for 16 -month-old rats. Treadmill speed was increased by 5 and $3 \mathrm{~m} \mathrm{~min}^{-1}$ every $3 \mathrm{~min}$ for the young and older rats, respectively. All tests were separated by 3 days.

Measurement of oxygen uptake. Experimental parameters, including resting metabolic rate (RMR), volume of oxygen uptake $\left(\mathrm{VO}_{2}\right)$ and RER, were assessed using the Columbus Oxymax Lab Animal Monitoring System and an animal treadmill chamber. $\mathrm{O}_{2}$ and $\mathrm{CO}_{2}$ concentrations were measured as a percentage of the incoming continuous flow. A gas analyser was calibrated with ambient air and a reference gas $\left(20.6 \% \mathrm{O}_{2}\right.$ and $0.501 \% \mathrm{CO}_{2}+\mathrm{N}_{2}$ ) in a room with stable temperature and humidity. The rats' body masses were measured. Air was pumped through the treadmill chamber at a flow rate of 5.0 LPM. Samples of extracted air were detected by the oxygen and carbon dioxide analysers. We measured the RMRs after the rats had rested for $10 \mathrm{~min}$ in the test chamber to avoid possible external stress stimulus. The test protocols were performed, and data were collected every $30 \mathrm{~s}$. Each rat had a 5 min warm up at $40-50 \%$ estimated $\mathrm{VO}_{2 \max }$ prior to the test. We used various criteria to confirm that $\mathrm{VO}_{2 \max }$ was elicited during the test. The criteria were as follows: the increase in $\mathrm{VO}_{2}$ was less than $5 \%$ with the increased workload, RER was above 1.00 and exhaustion characteristics (unwilling running, feeble kicking of hind legs and mental sluggishness) were observed ${ }^{22,23}$. Once any two of the above criteria were met, we stopped the test and recorded the $\mathrm{VO}_{2 \max }$ value.

Statistical analysis. Measurement results were presented as mean \pm standard deviation. Statistical analysis was performed using SPSS software (SPSS 22.0 for Windows, IBM SPSS Statistics). The assumptions of normality and variance homogeneity were tested. We conducted repeated measures to examine the differences in $\mathrm{VO}_{2 \max }$ indicators over the three procedures. One-way ANOVA was conducted to compare all measurements and multiple comparisons by least significant difference or Dunnett's test among groups. A Kruskal-Wallis test was used for non-normally distributed data. The level of significance was set at $p<0.05$.

Received: 10 October 2019; Accepted: 25 June 2020

Published online: 13 July 2020

\section{References}

1. Ross, R. et al. Importance of assessing cardiorespiratory fitness in clinical practice: A case for fitness as a clinical vital sign: A scientific statement from the American Heart Association. Circulation 134, e653-e699. https://doi.org/10.1161/CIR.0000000000 000461 (2016)

2. Medicine, A. C. o. S. ACSM's Guidelines for Exercise Testing and Prescription 10th edn, 148-150. (Wolter Kluwer, Alphen aan den Rijn, 2018).

3. Blair, S. N. et al. Physical fitness and all-cause mortality. A prospective study of healthy men and women. JAMA 262, 2395-2401 (1989).

4. Sui, X., LaMonte, M. J. \& Blair, S. N. Cardiorespiratory fitness as a predictor of nonfatal cardiovascular events in asymptomatic women and men. Am. J. Epidemiol. 165, 1413-1423. https://doi.org/10.1093/aje/kwm031 (2007).

5. Sawada, S. S. et al. Cardiorespiratory fitness, body mass index, and cancer mortality: A cohort study of Japanese men. BMC Public Health 14, 1012. https://doi.org/10.1186/1471-2458-14-1012 (2014).

6. Levine, B. D. $\mathrm{VO}_{2, \max }$ : What do we know, and what do we still need to know?. J. Physiol. 586, 25-34. https://doi.org/10.1113/jphys iol.2007.147629 (2008)

7. Milanovic, Z., Pantelic, S., Covic, N., Sporis, G. \& Krustrup, P. Is recreational soccer effective for improving VO $_{2 m a x}$ : a systematic review and meta-analysis. Sports Med. 45, 1339-1353. https://doi.org/10.1007/s40279-015-0361-4 (2015).

8. Coquart, J. B., Garcin, M., Parfitt, G., Tourny-Chollet, C. \& Eston, R. G. Prediction of maximal or peak oxygen uptake from ratings of perceived exertion. Sports Med. 44, 563-578. https://doi.org/10.1007/s40279-013-0139-5 (2014).

9. Edvardsen, E., Hem, E. \& Anderssen, S. A. End criteria for reaching maximal oxygen uptake must be strict and adjusted to sex and age: A cross-sectional study. PLoS ONE 9, e85276. https://doi.org/10.1371/journal.pone.0085276 (2014).

10. Bedford, T. G., Tipton, C. M., Wilson, N. C., Oppliger, R. A. \& Gisolfi, C. V. Maximum oxygen consumption of rats and its changes with various experimental procedures. J. Appl. Physiol. Respir. Environ. Exerc. Physiol. 47, 1278-1283. https://doi.org/10.1152/jappl 1979.47.6.1278 (1979).

11. Leandro, C. G. et al. A program of moderate physical training for Wistar rats based on maximal oxygen consumption. J. Strength Cond. Res. 21, 751-756. https://doi.org/10.1519/r-20155.1 (2007).

12. Hoydal, M. A., Wisloff, U., Kemi, O. J. \& Ellingsen, O. Running speed and maximal oxygen uptake in rats and mice: Practical implications for exercise training. Eur. J. Cardiovasc. Prev. Rehabil. 14, 753-760. https://doi.org/10.1097/HJR.0b013e3281eacef1 (2007).

13. Wisloff, U., Helgerud, J., Kemi, O. J. \& Ellingsen, O. Intensity-controlled treadmill running in rats: VO(2 max $)$ and cardiac hypertrophy. Am. J. Physiol. Heart Circ. Physiol. 280, H1301-1310. https://doi.org/10.1152/ajpheart.2001.280.3.H1301 (2001).

14. Lawler, J. M., Powers, S. K., Hammeren, J. \& Martin, A. D. Oxygen cost of treadmill running in 24-month-old Fischer-344 rats. Med. Sci. Sports Exerc. 25, 1259-1264 (1993).

15. Astrand Perolof, R. K. Textbook of work physiology : Physiological bases of exercise. Physiother. Theory Pract. 20, 73-73 (1986).

16. Chavanelle, V. et al. Comparison of oxygen consumption in rats during uphill (concentric) and downhill (eccentric) treadmill exercise tests. J. Sports Sci. Med. 13, 689-694 (2014).

17. Robergs, R. An exercise physiologist's "contemporary" interpretations of the "ugly and creaking edifices" of the $\mathrm{VO}_{2 \mathrm{max}}$ concept. J. Exerc. Physiol. Online 4, 1-44 (2001).

18. Taylor, H. L., Buskirk, E. \& Henschel, A. Maximal oxygen intake as an objective measure of cardio-respiratory performance. J. Appl. Physiol. 8, 73-80. https://doi.org/10.1152/jappl.1955.8.1.73 (1955). 
19. Taylor, C. R., Schmidt-Nielsen, K. \& Raab, J. L. Scaling of energetic cost of running to body size in mammals. Am. J. Physiol. 219, 1104-1107. https://doi.org/10.1152/ajplegacy.1970.219.4.1104(1970).

20. Fitzsimons, D. P., Bodell, P. W., Herrick, R. E. \& Baldwin, K. M. Left ventricular functional capacity in the endurance-trained rodent. J. Appl. Physiol. 69, 305-312. https://doi.org/10.1152/jappl.1990.69.1.305 (1990).

21. Mazzeo, R. S. \& Horvath, S. M. Effects of training on weight, food intake, and body composition in aging rats. Am. J. Clin. Nutr. 44, 732-738. https://doi.org/10.1093/ajcn/44.6.732 (1986).

22. Swiatkiewicz, M. et al. Increases in brain (1)H-MR glutamine and glutamate signals following acute exhaustive endurance exercise in the rat. Front. Physiol. 8, 19. https://doi.org/10.3389/fphys.2017.00019 (2017)

23. Matsui, T. et al. Brain glycogen supercompensation following exhaustive exercise. J. Physiol. 590, 607-616. https://doi.org/10.1113/ jphysiol.2011.217919(2012).

\section{Acknowledgements}

This study was supported by the National Natural Science Foundation of China (Grant No. 11775059), the China Postdoctoral Science Foundation (Grant No. 2018T110076) and the Fundamental Research Foundation of the China Institute of Sport Science (Grant Nos. 17-18 and 17-19).

\section{Author contributions}

F.Q. and Y.D. contributed equally in the ideas and writing of the manuscript. F.Q., J.Z. and S.W. conceived and designed the research. Y.D., Z.W., M.X., C.Q. and F.Q. performed the experiments. J.Z., Y.D., M.X. and Y.Y. analysed the data. F.Q., J.Z. and S.W. interpreted the experimental results. Y.D., Z.W. and F.Q. prepared the figures. Y.D. and F.Q. drafted the manuscript. F.Q., J.Z., S.W., C.Q. and Y.Y. edited and revised the manuscript. JZ and FQ approved the final version of the manuscript.

\section{Competing interests}

The authors declare no competing interests..

\section{Additional information}

Correspondence and requests for materials should be addressed to J.Z.

Reprints and permissions information is available at www.nature.com/reprints.

Publisher's note Springer Nature remains neutral with regard to jurisdictional claims in published maps and institutional affiliations.

(c) (i) Open Access This article is licensed under a Creative Commons Attribution 4.0 International cc) License, which permits use, sharing, adaptation, distribution and reproduction in any medium or format, as long as you give appropriate credit to the original author(s) and the source, provide a link to the Creative Commons license, and indicate if changes were made. The images or other third party material in this article are included in the article's Creative Commons license, unless indicated otherwise in a credit line to the material. If material is not included in the article's Creative Commons license and your intended use is not permitted by statutory regulation or exceeds the permitted use, you will need to obtain permission directly from the copyright holder. To view a copy of this license, visit http://creativecommons.org/licenses/by/4.0/.

(C) The Author(s) 2020 